\title{
Knowledge and acceptance of interventions aimed at reducing sugar intake in Portugal
}

\author{
Marília Prada* ๑), David L Rodrigues, Cristina A Godinho, Diniz Lopes and \\ Margarida V Garrido \\ Department of Social and Organizational Psychology, Instituto Universitário de Lisboa (Iscte-IUL), CIS_Iscte, \\ Lisboa 1640-026, Portugal
}

Submitted 13 December 2019: Final revision received 15 May 2020: Accepted 10 June 2020

\begin{abstract}
Objective: Governments worldwide have been implementing interventions aimed at improving citizens' dietary habits. Examining how individuals perceive these interventions is relevant for promoting future policies in this area, as well as informing the way they are designed and implemented. In the current study, we focused on interventions aimed at reducing sugar intake in Portugal, given the current high sugar consumption patterns in the population.

Design: Online survey to assess which interventions are the most salient and receive greater public support.

Setting: Portugal.

Participants: 1010 (76.7\% female, $M_{\text {Age }} 36 \cdot 33$, sD 13.22).

Results: Data from a free-recall task showed that only about one-third of participants reported knowing about these interventions, namely those related to taxation, weight restrictions in individual sugar packets and limited availability of products with high sugar content. We also found evidence of high support for the eight interventions presented (except for replacing sugar by artificial sweeteners), positive attitudes towards the need of reducing sugar intake in the Portuguese population and high agreement with the importance of reducing sugar intake across all age groups, particularly among children. Participants also indicated paying attention to the amount of sugar in their diets and a low self-reported frequency of consumption of high sugary foods and beverages. A hierarchical regression analysis suggested that these variables were significantly associated with the overall acceptance of interventions, independently of social-demographic variables (i.e., age, education and sex).

Conclusion: By examining how people perceive and accept different interventions targeting the reduction of sugar intake, the current work aims to support policymaking in this domain.
\end{abstract}

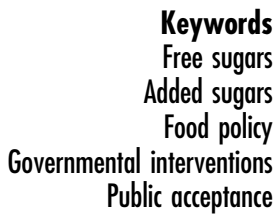

Keywords

Free sugars

Food policy

Public acceptance
Overconsumption of food products with high sugar content contributes to an unhealthy diet. Excessive sugar consumption not only increases overall energy intake but is also often associated with a lower intake of more nutritionally adequate energy content, which may result in multiple negative health outcomes (e.g., weight gain, diabetes, dental diseases $\left.{ }^{(1)}\right)$. Several health authorities have already issued recommendations regarding the intake of free or added sugars (for a review, see ${ }^{(2)}$ ). For instance, the WHO issued guidelines for the intake of free sugars (i.e., '... monosaccharides and disaccharides added to foods and beverages by the manufacturer, cook or consumer and sugars naturally present in honey, syrups, fruit juices and fruit juice concentrates'), stating that it should be limited to $<10 \%$ (ideally $5 \%$ ) of the total daily energy intake ${ }^{(1)}$. To illustrate, for a person with a 2000 $\mathrm{kcal} /$ daily intake, free sugars intake should be $<50 \mathrm{~g}$ (or about twelve teaspoons)/d.

A recent review of representative surveys across eleven European countries found that added sugars represent between $7 \cdot 3 \%$ (in Norway) and $11.4 \%$ (in the UK) of adults' energy intake ${ }^{(3)}$. For children and teens, these numbers are even higher (from $11 \%$ in Denmark to $16.8 \%$ in the Netherlands). According to the National Food, Nutrition 
and Physical Activity Survey ${ }^{(4,5)}$, in Portugal, free sugars contribute on average to $7.5 \%$ of total daily energy intake (9.6\% for children and 10.5\% for teens). Moreover, the results showed a high prevalence of excessive consumption of free sugars (i.e., above $10 \%$ of total energy intake) for the overall population (24.3\%), for children (40.7\%) and for teens (48.7\%), suggesting an imperative need to address this problem.

Reducing population intake of free sugars is a complex issue that requires government action, along with the engagement of other parties of the food system such as the production industry, retailers, hospitality sector, as well the media ${ }^{(6)}$. Change may be attained by implementing strategies such as population education (e.g., national dietary guidelines), point-of-purchasing labelling (e.g., food package nutrition fact panels), fiscal (dis)incentives (e.g., soft drinks taxes), industry quality standards (e.g., mandatory or recommended limits for sugar, trans fat, etc.) and food marketing standards (e.g., limited marketing towards children of products that fail to meet nutrition standards $\left.{ }^{(7,8)}\right)$.

We are particularly interested in examining how individuals perceive and accept governmental interventions aimed at reducing sugar intake. Assessing public perception is relevant because public has shown to be a key enabler for political action, as decision-makers respond favourably to issues supported by their electorates ${ }^{(9,10)}$. Moreover, public perception also potentially shapes the design, implementation and compliance with a given policy (e.g., $\left.{ }^{(11)}\right)$. Next, we briefly present an overview of the governmental measures that have been developed in the Portuguese context.

\section{Current governmental interventions aimed at reducing sugar intake in Portugal}

In 2016, the Portuguese government developed a public health programme aiming, among other goals, to prevent diabetes and obesity through the promotion of health literacy ${ }^{(12)}$. Besides this focus on promoting citizens' capability to make informed choices about their health, multiple actions have also been implemented to promote healthier dietary habits (for a review, see ${ }^{(13)}$ ). For example, to reduce the excessive intake of sugar, salt and fat, there is a regulation defining which products may be sold in vending machines placed in national healthcare facilities ${ }^{(14)}$. This regulation was subsequently generalised to the products sold (or advertised) in cafeterias placed in these facilities ${ }^{(15)}$. For instance, whereas some products are forbidden (e.g., cakes, pastry, soft drinks), others can be allowed if complying with guidelines regarding composition (e.g., cookies with up to $20 \%$ of sugar content) or portion sizes (e.g., chocolates without filling may be available in portions up to $50 \mathrm{~g}$ ).
Another action that illustrates an environmental intervention to facilitate healthier choices is the reduction of the weight of individual sugar packets. These packets usually contained $8 \mathrm{~g}$ of sugar and were reduced to $5 / 6 \mathrm{~g}$ via an agreement between the ministry of health and food industry representatives ${ }^{(16)}$. A revised agreement defines that in 2020 single-serve packets should contain up to $4 \mathrm{~g}$ of sugar. Regarding population-based information campaigns, a recent 2018 advertisement, disseminated on TV and social media, aimed to raise awareness about hidden sugars.

Increased taxation on sugar-sweetened beverages (SSB) was approved in the state budget in 2017 (i.e., each hectolitre of non-alcoholic beverages up to $80 \mathrm{~g}$ of sugar/l was taxed by $€ 8 \cdot 22$, and the taxation roughly doubled for beverages exceeding that amount of sugar $\left.{ }^{(17)}\right)$. Although these taxes were essentially maintained in the state budget for $2018^{(18)}$, they were extensively reviewed for $2019^{(19)}$, further encouraging the reduction of sugar content.

Given that these interventions are recent, there is still, to our knowledge, no available information regarding their impact. An exception refers to the impact of taxation, with preliminary data suggesting a $11 \%$ reduction of the total energy intake through SSB consumption ${ }^{(20,21)}$. This pattern is in line with previous results in other countries showing that these types of fiscal measures have been effective in promoting reduced sugar intake ${ }^{(22)}$.

\section{Consumer acceptance of interventions to regulate sugar intake elsewhere}

Several studies have examined how individuals evaluate policy interventions aimed at changing various behaviours, such as tobacco and alcohol use, as well as diet and physical activity (for a review, see ${ }^{(23)}$ ). We will focus on interventions designed to improve diet quality. For example, a study found that British participants highly supported policies for weight management such as healthy lifestyle campaigns and food labelling (i.e., fat and energy content of foods in restaurants), but not taxation of unhealthy foods ${ }^{(24)}$. Another study showed that Australian participants agreed with government-driven actions to address overweight and obesity rates, with interventions restricting the advertisement of unhealthful food to children and to a lower extent with fiscal actions ${ }^{(25)}$. A recent study ${ }^{(26)}$ also examined the acceptance level of various healthy eating nudges for American consumers and found that descriptive nutritional labelling obtained the highest approval. Overall, as suggested by a survey including five European countries, the more intrusive the intervention (e.g., bans or taxations), the lower the support ${ }^{(27)}$. Likewise, another cross-national study with six European countries showed that the least intrusive interventions (i.e., those that entail information provision by the government) were supported across countries ${ }^{(28)}$. However, significant differences emerged for the overall approval of the total set of nine interventions 
(e.g., around $74 \%$ support was found in Italy, the UK and France, followed by Germany with $69 \%$ and then by Hungary and Denmark with $57 \cdot 1$ and $54 \%$, respectively).

Although some inferences may be drawn from these studies, research specifically focusing on how consumers perceive (and react to) different governmental interventions to reduce sugar intake is still scarce. Some studies have taken a qualitative approach to this issue. For instance, a study analysing the content of American press coverage of the SSB taxation debate found mainly protaxation arguments (e.g., health and financial benefits of taxation $\left.^{(29)}\right)$. More recently, an examination of public responses to an SSB tax proposal in the UK (i.e., readers' comments to online news covering this intervention) showed that consumers perceived this measure as a challenge to the autonomy of individuals who should be responsible for their own diet. Mistrust in the authorities (e.g., government, industry, public health experts) also emerged, namely regarding the true purpose of the tax (i.e., raise revenue instead of reducing sugar intake) or of alternatives (i.e., replacing sugar by artificial sweeteners $^{(30)}$ ).

We identified two important contributions focused on the public acceptance of a set of government interventions aimed at reducing sugar intake. First, a study by Petrescu et al. ${ }^{(31)}$ compared how British and American participants rated the acceptability of five interventions aimed at reducing the intake of SSB. Consumer education was rated as the most acceptable and taxation the least acceptable strategy. No overall differences were found according to country, with the exception that British participants were more in favour of reducing portion sizes. The second important contribution is provided by the study by Hagmann et al. ${ }^{(32)}$ that included a large sample of Swiss participants. Specifically, participants were asked to rate their agreement, using seven-point rating scales, with the implementation of eight strategies, including public health campaigns, reducing sugar content in products or replacing sugar with artificial sweeteners or nudging (e.g., reducing the availability of foods containing high sugar content). Overall, participants agreed with most interventions, particularly with the labelling of sugar content, followed by public health campaigns. Only three interventions were rated below the agreement scale midpoint: restriction of portion sizes of foods high in sugar, taxation and replacing sugar in specific food categories (breakfast cereals and yogurt) by artificial sweeteners.

In the current work, we examined public acceptance of different interventions aimed at reducing sugar intake in Portugal. To our knowledge, Portugal was not included in previous studies examining the acceptance of interventions promoting healthy eating in general $^{(27,28)}$, or reduction of sugar intake in particular ${ }^{(31,32)}$. To that end, we assessed the agreement level with the set of sugar reduction interventions described in Hagmann et al.'s study ${ }^{(32)}$. In addition to identifying which interventions received greater support, we explored how the overall acceptance of the interventions is shaped by variables related to sugar consumption (e.g., consciousness of sugar intake, frequency of sugary products consumption) as well as by individual characteristics. For instance, individuals who pay more attention to their sugar intake also show greater support of interventions ${ }^{(32)}$. Previous research has also shown that higher acceptance may be found among women ${ }^{(23,25,28,32)}$, older participants ${ }^{(23)}$, participants with tertiary education ${ }^{(25)}$ and those with children ${ }^{(25)}$. Moreover, we also assessed the extent to which consumers perceived reducing sugar intake in the Portuguese population as an important and urgent issue and which age groups should be prioritised.

To the extent that Portuguese health authorities have recently implemented several actions (e.g., taxation, restrictions on foods and beverages available in healthcare facilities), we also aimed to explore which of these interventions were more salient to the participants. Specifically, just prior to the acceptance ratings, we included a free-recall task to examine whether participants were aware and remembered the Portuguese government actions intended to reduce sugar intake.

\section{Method}

\section{Participants}

The current study included 1010 Portuguese volunteers ( $76.7 \%$ female, $22.9 \%$ male and $0.4 \%$ other) aged between 18 and 82 years ( $M 36 \cdot 33$ years, sD $13 \cdot 22)$. Most of the participants reported having at least a college degree (78.8\%), to be employed $(77.5 \%)$, to be in a cohabiting romantic relationship (50.0\%) and not having children in the household (66.5\%). Moreover, most participants reported following a regular omnivorous diet (72.5\%) and a BMI within the normal weight range (i.e., 18.5-24.9, 58.5\%).

\section{Instruments and procedure}

Participants were invited, through an institutional email and social networks, to collaborate on a web survey about food habits. When clicking on the provided link, they were directed to a secure webpage hosted in Qualtrics containing information about the goals of the study, its expected duration (approximately $15 \mathrm{~min}$ ) and ethical considerations (i.e., anonymity, confidentiality and the possibility to withdraw from the study at any point). The only incentive to participate was the opportunity to win one of the three commercial vouchers $(€ 50)$. The survey was administered in European Portuguese, and participation was restricted to Portuguese adults. After agreeing to collaborate in the study, participants were presented with a set of socio-demographic questions (e.g., sex, age, level of education, number of children in the household) and with the main study variables. As the survey was part of a broader project, we will only describe the relevant measures for the current paper. 
First, participants responded to an item assessing sugar consciousness $^{(32)}$ (i.e., How much attention do you pay to the sugar content in your diet?, from $1=$ Not at all to $7=$ Very much). Next, participants indicated their general frequency of consumption of foods and beverages with high sugar content by selecting one of the seven options (from $1=$ Never or less than once $a$ month to $7=$ More than once a day). Participants were then asked about their attitudes towards reducing sugar intake in the Portuguese population using two rating scales: 'In your opinion, reducing sugar intake for the Portuguese population is...' (i) from $1=$ Not very important to $7=$ Very important and (ii) from $1=$ Not very urgent to $7=$ Very urgent . Both items were positively and strongly correlated, $r 0.73$, $p<0.001$, and were combined into a single index.

Subsequently, a free-recall task regarding interventions aimed at reducing sugar intake was introduced. Specifically, participants were asked 'Do you recall any official intervention or policy aimed at reducing sugar intake in the Portuguese population?' (Yes/No). Participants who selected 'yes' were asked to list and describe, in their own words, all the interventions they could remember.

After this task, we assessed their general acceptance of interventions to reduce sugar consumption by adapting the instrument from Hagmann et al. ${ }^{(32)}$ to European Portuguese. Across items, we replaced the expression 'foods high in sugar' for 'products high in sugar' to include both foods and beverages. Participants were asked 'Please indicate to what extent do you agree with each of the following governmental strategies aimed at reducing sugar intake in the Portuguese population' using seven-point rating scales (from $1=$ Do not agree at all to $7=$ Fully agree). Specifically, the eight items were related to (i) reducing the availability of high sugary products ('The availability of products containing high levels of sugar should be reduced' (e.g., no sales at vending machines)), (ii) taxation ('Increased taxation should be applied to products with high sugar content'), (iii) advertisement ban ('Advertisements for products high in sugar should be forbidden'), (iv) reducing portion size ('There should be a limit of the portion size of foods high in sugar'), (v) labelling ('The sugar content should be clearly visible on a label on the package of products high in sugar'), (vi) sugar reduction in products ('There should regulations for the food industry about the maximum amount of sugar that products may contain'), (vii) substitution of sugar by artificial sweeteners ('Sugar in products should be replaced by artificial sweeteners') and (viii) public health campaigns (e.g., 'Population-based information campaigns promoting a reduction of sugar content in the diet should be conducted'). This scale presented an acceptable reliability in the current study ( $\alpha=0.77)$.

Finally, participants were asked to indicate how important (from $1=$ Not very important to $7=$ Very important) would be to reduce sugar intake in five age-groups (i.e., 'children up to 6 years old', 'children from 6 to 12 years old', 'teenagers', 'adults' and 'elderly'; $\alpha=0.84$ ).

At the end of the survey, participants were asked additional control measures, namely to indicate their diet(s) type(s), height and weight (open-ended answers, including 'I don't know/I rather not say' options), and finally asked to rate their overall health status (from $1=$ Very bad to $\left.7=\operatorname{Very} \operatorname{good}^{(33)}\right)$.

\section{Results}

Only completed questionnaires were retained, and statistical analyses were performed using IBM SPSS Statistics version 25 .

\section{Interventions: free-recall task}

Results showed that 649 (64.3\%) participants did not remember any specific intervention aimed at reducing sugar intake in the Portuguese population, whereas 361 $(35.7 \%)$ participants indicated remembering such interventions. However, forty-six did not indicate any specific measure. The remaining 315 participants indicated between one and four interventions ( $M 1.35$, SD 0.58), in a total of 425 interventions. Responses were then discussed and categorised by three independent judges. Results are summarised in Table 1, including examples of participants' responses per category.

As shown in Table 1, the most frequently mentioned intervention was increasing prices or taxation for products with high sugar content, particularly for soft drinks, followed by the reduction of the quantity of sugar in individual sugar packets. The third most frequent intervention was related to the limited availability of products with high sugar content in healthcare or education facilities, either in vending machines or in cafeterias. Less than $10 \%$ of the interventions mentioned were related to raising public awareness or promoting consumer knowledge about sugar.

\section{Descriptive results and correlations}

As shown in Table 2, overall, participants supported the interventions, considered important reducing sugar intake across age groups and had positive attitudes towards sugar intake reduction in Portugal. They also reported paying attention to sugar intake in their own diet, to ingesting sugar less frequently and to be in good general health.

Correlations between study variables are also presented in Table 2. Overall, the acceptance of interventions designed to reduce sugar intake was positively correlated with the ratings of importance of reducing sugar intake across all age groups, $p<0.001$ and positive attitudes towards sugar reduction for the Portuguese population in general, $p<0 \cdot 001$. These latter two variables were also positively correlated, $p<0 \cdot 001$. Moreover, we also observed 


\section{Public Health Nutrition}

Table 1 Categorisation of recalled interventions aimed at reducing sugar intake*

\begin{tabular}{ll}
\hline Category & Example of participant responses
\end{tabular}

Taxation

Increased prices or taxes...

General

.. for products high in sugar

\section{Beverages}

.. for soft drinks; juices high in sugar

Individual sugar packets

Reduced weight for individual sugar packets used in the hospitality sector

Limit availability

Limitation or restriction of products available according to..

Context (i.e., type of facility in which the restriction is applied)

Mean (i.e., type of mean by which the restriction is applied)

Campaigns/actions

Advertising in different means (TV, press, leaflets, posters) and actions

to raise awareness or to promote health literacy

\section{Industry regulation}

Reduction or regulation of sugar in food and beverages production industry

Labelling

Information presented in food and beverages packages

Educational approach

Interventions aimed at educating consumers
Taxation of products with excessive sugar

Increase VAT for products with high sugar content

Higher prices for sweeter foods

Increased taxation (and consequently price) for soft drinks

Increase price for soft drinks according to its sugar content

Raise prices for soft drinks and juices with lots of sugar

Reduction, by law, of the quantity of sugar in individual packets

Portion reduction in individual sugar packets used in coffee shops

Reduction from 8 to 6 grams in individual sugar packets

Healthcare Facilities (exclusive reference to hospitals; health centres)

Elimination of sugary products in hospitals

Education Facilities (exclusive reference to schools)

Banning products with excessive sugar from schools

General (both contexts or context not specified)

Forbid the sale of high sugar products on public spaces

Automated selling (vending machines)

Remove foods with excessive sugars from vending machines

Traditional selling (cafeteria, canteen, etc.)

Restrict the sale of cakes in school cafeterias

General both means or not specified)

Remove any kind of sweets from schools or public places

More informative advertisements on TV during prime time

Ad campaigns to reduce the quantity of sugar in soft drinks and yogurts Awareness campaigns developed by healthcare professionals

Laws that make mandatory the reduction of sugar and salt used in food

Reduction of added sugars in grocery products and beverages

Control of the maximum quantity of sugar permitted in soft drinks

Nutritional traffic-light in labels

Symbols on packages

Clearer labelling 


\section{Nestic Health Nutrition}

Table 1 Continued

Category

Example of participant responses

Teaching people to eat healthful and tasty food

Conferences in school from the first year of education

Integrated training at school level

Inclusion of fruit in school snacks

Reduce sugar content of school milk with chocolate

Distribution of plain milk to children in schools

Miscellaneous interventions (e.g., individual and unspecific strategies)

Consume vegetables at every meal

Programs to support diabetic people

Use of artificial sweeteners (which is even worse...)

*Percentages calculated based on the total number of intervention

tResults refer to the frequencies of sub-categories in relation to the total frequency of the category

Table 2 Overall descriptive results $(\mathrm{M}, \mathrm{SD}, \mathrm{Cl})$ and correlations

\begin{tabular}{|c|c|c|c|c|c|c|c|c|c|c|c|}
\hline & \multicolumn{4}{|c|}{ Descriptives } & & & & & & & \\
\hline & \multirow[b]{2}{*}{ Mean } & \multirow[b]{2}{*}{ SD } & \multicolumn{2}{|c|}{$95 \% \mathrm{Cl}$} & \multicolumn{7}{|c|}{ Correlations } \\
\hline & & & LB & UB & 1 & 2 & 3 & 4 & 5 & 6 & 7 \\
\hline \multicolumn{12}{|l|}{ Variable } \\
\hline 1. Acceptance of interventions & 5.49 & 1.00 & 5.43 & 5.54 & & - & & & & & \\
\hline 2. Importance of reducing sugar intake (all age groups) & $6 \cdot 50$ & 0.77 & $6 \cdot 46$ & 6.55 & $0.41^{* * *}$ & - & & & & & \\
\hline 3. Attitudes towards sugar intake reduction in Portugal & $6 \cdot 64$ & 0.74 & $6 \cdot 60$ & 6.69 & $0.37^{\star \star *}$ & $0.38^{\star \star \star}$ & - & & & & \\
\hline 4. Sugar consciousness & 5.44 & 1.55 & 5.34 & 5.53 & $0.29^{* * *}$ & $0.25^{\star \star *}$ & $0 \cdot 26^{\star * \star}$ & - & & & \\
\hline 5. Frequency of sugar intake & 3.23 & 1.55 & $3 \cdot 14$ & $3 \cdot 13$ & $-0 \cdot 18^{\star * *}$ & $-0 \cdot 10^{\star *}$ & $-0 \cdot 15^{\star \star *}$ & $-0.35^{\star * *}$ & _- & & \\
\hline 6. Perceived general health & $5 \cdot 25$ & 1.04 & $5 \cdot 19$ & $5 \cdot 31$ & 0.05 & $0 \cdot 13^{\star \star \star}$ & $0.09^{\star \star}$ & $0 \cdot 20^{\star \star \star}$ & $-0 \cdot 19^{\star \star \star}$ & - & \\
\hline 7. Age & 36.33 & $13 \cdot 22$ & 35.51 & 37.15 & $0 \cdot 11^{\star *}$ & 0.06 & $0.08^{\star *}$ & $0.17^{\star \star \star}$ & $-0 \cdot 17^{\star \star \star}$ & -0.04 & - \\
\hline 8. BMl & 23.92 & 4.21 & 23.65 & $24 \cdot 19$ & -0.02 & -0.05 & -0.01 & -0.01 & 0.05 & $-0 \cdot 29^{* * *}$ & $0.28^{* * *}$ \\
\hline
\end{tabular}

$\mathrm{LB}$, lower bound of the confidence interval; UB, upper bound of the confidence interval.

${ }^{* *} p<0.010,{ }^{* * *} p<0.001$

†All variables refer to the full sample ( $n$ 1010), except for BMI due to missing values in height or weight ( $n$ 951). 
positive associations between these three variables with sugar consciousness, all p's $<0.001$ and negative associations with the self-reported frequency of consumption of high sugary foods and drinks, all $p$ 's $\leq 0 \cdot 001$. Self-reported general health was also positively correlated with ratings of importance of reducing sugar intake across all age groups, $p<0.001$, and attitudes towards reduction for the Portuguese population in general, $p=0.004$. BMI was only positively associated with age, $p<0.001$, and negatively associated with perceived general health, $p<0.001$.

\section{Acceptance of interventions designed to reduce sugar intake}

For all interventions, acceptance ratings varied between 1 and 7. The repeated measures ANOVA (with HuynhFeldt correction, as sphericity assumption was not verified) showed that the level of acceptance differed significantly between interventions, $F(5 \cdot 185,230 \cdot 22)=605 \cdot 32$, $M S E=1492 \cdot 85, p<0.001, \eta_{p}^{2}=0.38$. Post hoc tests with Bonferroni correction showed significant differences between all strategies, all p's <0.046, except between 'reducing availability' and 'sugar reduction in products'.

Overall, participants reported accepting all interventions (see Table 3), with the exception of replacing sugar in food products by artificial sweeteners, which obtained the lowest acceptance level. The most accepted intervention was the one related to sugar labelling (i.e., 'The sugar content should be clearly visible on a label on the package of foods high in sugar').

Sex differences in the acceptance of the interventions are shown in Fig. 1. Women ( $v$. men) showed higher acceptance for most interventions, all $p$ 's $<0 \cdot 027$. Still, no significant sex differences were found for taxation $t(1004)=1 \cdot 80, \quad p=0.080, d=0 \cdot 11$, advertisement ban, $t(1004)=1 \cdot 88, p=0.066, d=0 \cdot 12$, and artificial sweeteners, $t<1$.

Overall, no differences were detected according to the level of education, all $p$ 's $\geq 0 \cdot 260$, except for one intervention: participants with higher education reported greater

Table 3 Acceptance ratings for different interventions (overall sample)*

\begin{tabular}{llllll}
\hline & & & \multicolumn{2}{c}{$95 \% \mathrm{Cl}$} \\
\cline { 4 - 6 } & & & & \\
& Mean & SD & LB & UB \\
\hline Interventions & & & & \\
1. Reducing availability & $5.97^{\mathrm{e}}$ & 1.56 & 5.87 & 6.07 \\
2. Taxation & $5.25^{\mathrm{c}}$ & 1.93 & $5 \cdot 14$ & 5.37 \\
3. Advertisement ban & $4.72^{\mathrm{b}}$ & 1.97 & 4.59 & 4.84 \\
4. Reducing portion size & $5.82^{\mathrm{d}}$ & 1.54 & 5.72 & 5.91 \\
5. Labelling & $6.45^{\mathrm{g}}$ & 0.99 & 6.39 & 6.51 \\
6. Sugar reduction in products & $6.02^{\mathrm{e}}$ & 1.53 & 5.93 & 6.12 \\
7. Artificial sweeteners & $3.32^{\mathrm{a}}$ & 1.96 & 3.19 & 3.44 \\
8. Public health campaigns & $6.35^{\dagger}$ & 1.08 & 6.28 & 6.42 \\
Overall & 5.49 & 1.00 & 5.43 & 5.55 \\
& & & &
\end{tabular}

*Different superscripts $(a-g)$ indicate different levels of acceptance between interventions. support for the taxation of high sugar products $(M 5 \cdot 37$, SD 1.83) than those with lower levels of education $(M 4.83$, sD $2 \cdot 20), t(298 \cdot 77)=3 \cdot 28, p=0.001, d=0 \cdot 34$. We also found that participants with $(v$. without) children in the household agreed more with the advertisement ban, $t(1008)=2 \cdot 07, p=0 \cdot 038, d=0 \cdot 13$. No other differences were detected, all $p$ 's $\geq 0 \cdot 164$.

Age was positively (but weakly) correlated with the acceptance of the following interventions: advertisement ban ( $r 0.21, p<0.001)$, labelling ( $r 0.07, p=0.027)$, sugar reduction in products $(r 0.09, p=0.004)$ and public health campaigns $(r 0 \cdot 11, p=0 \cdot 001)$. In contrast, age was negatively associated with the acceptance of replacing sugar by artificial sweeteners, $r-0 \cdot 06, p=0 \cdot 044$. Finally, we did not find overall differences according to BMI. The only difference that approached conventional levels of significance was that overweight ( $v$. non-overweight) participants tended to be more supportive of replacing sugar by artificial sweeteners, $t(585.11)=1.97, \quad p=0.052$, $d=0 \cdot 16$, all other $p$ 's $\geq 0 \cdot 229$.

\section{Prioritised age-groups for sugar reduction}

The repeated measures ANOVA (with Huynh-Feldt correction, as sphericity assumption was not verified) showed that the perceived importance of reducing sugar consumption varied according to target age group, $F(2 \cdot 642$, 665.84 $)=80 \cdot 39$, $M S E=56 \cdot 21, p<0 \cdot 001, \eta_{p}^{2}=0 \cdot 14$. Results are summarised in Table 4. Although participants evaluated the reduction of sugar consumption across age groups as highly important, post hoc tests with Bonferroni correction showed that adults were the least prioritised age group, all $p$ 's $<0.021$, followed by the elderly (but not different from teenagers, $p=0 \cdot 177$ ). The most prioritised target group for reducing sugar intake was children irrespective of their age (i.e., up to 12 years old), $p=0 \cdot 134$.

As shown in Table 4, women ( $v$. men) considered more important to reduce sugar intake across age groups, all $p$ 's $\leq 0.002$. We also found that participants with children ( $v$. without) in the household considered more important to reduce sugar intake for children, either up to 6 years old, $t(980 \cdot 61)=3 \cdot 20, p=0 \cdot 001, d=0 \cdot 20$, or up to 12 years old, $t(877.92)=2 \cdot 55, p=0.009, d=0 \cdot 17$. For teenagers, this sex difference was only marginal, $t(740 \cdot 23)=1.92$, $p=0.057, d=0.10$, and no differences were observed for the other age groups, all $p$ 's $\geq 0 \cdot 279$.

\section{Hierarchical regression analysis}

Table 5 presents the results of the hierarchical regression with general acceptance of interventions as the outcome variable. In each block, we entered individual characteristics (step 1) and variables related to sugar consumption (step 2). The final model was significant, $F(8,997)=41.88$, $M S E=31.40, p<0.001$, and explained $25 \%$ of the variance on interventions' acceptance. 


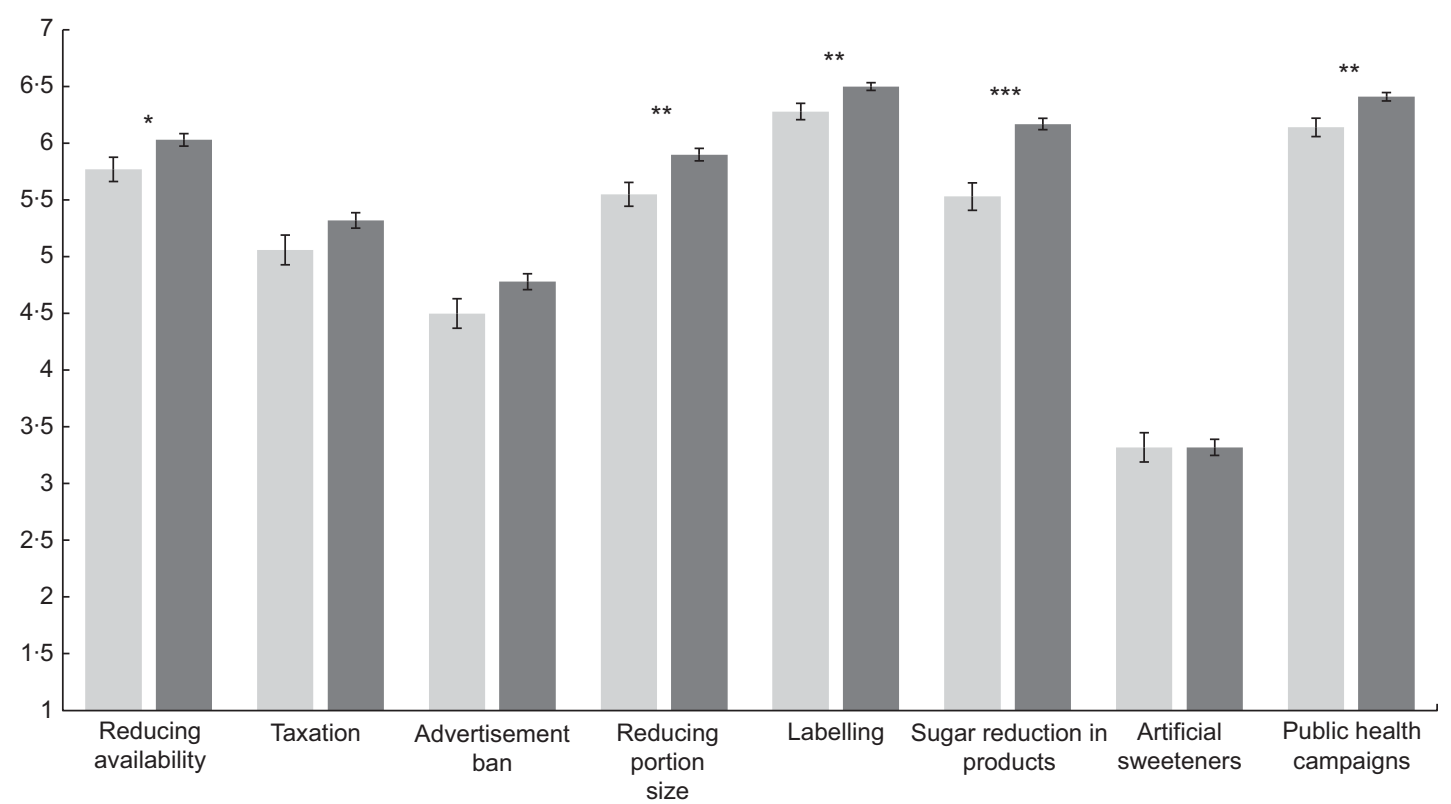

Fig. 1 Sex differences in the acceptance of the interventions. Results for multiple comparisons are corrected using 5000 bootstrap samples. Error bars represent SE. ${ }^{\star} p<0.05,{ }^{\star *} p<0.01,{ }^{\star * \star} p<0.001$. $\square$, men; $\square$, women

Table 4 Importance of sugar intake reduction for different age groups (overall sample and according to sex) ${ }^{\star}$

\begin{tabular}{|c|c|c|c|c|c|c|c|}
\hline & \multicolumn{3}{|c|}{ Overall sample ( $n$ 1010) } & \multicolumn{2}{|c|}{ Men $(n$ 231) } & \multicolumn{2}{|c|}{ Women $(n 775)$} \\
\hline & Mean & SD & $95 \% \mathrm{Cl}$ & Mean & SD & Mean & SD \\
\hline 1. Children $(<6$ years old) & $6 \cdot 72^{c}$ & 0.84 & $6 \cdot 67,6.77$ & $6 \cdot 51^{1}$ & 1.09 & $6 \cdot 78^{2}$ & 0.73 \\
\hline 2. Children (6-12 years old) & $6 \cdot 68^{c}$ & 0.82 & $6.63,6.73$ & $6 \cdot 48^{1}$ & 1.01 & $6 \cdot 74^{2}$ & 0.75 \\
\hline 3. Teenagers & $6 \cdot 46^{\mathrm{b}}$ & 1.01 & $6 \cdot 39,6.52$ & $6 \cdot 12^{1}$ & 1.26 & $6 \cdot 55^{2}$ & 0.90 \\
\hline 4. Adults & $6 \cdot 29^{a}$ & 1.07 & $6 \cdot 22,6 \cdot 35$ & $5 \cdot 87^{1}$ & 1.24 & $6 \cdot 41^{2}$ & 0.98 \\
\hline 5. Elders & $6 \cdot 37^{b}$ & 1.13 & $6 \cdot 30,6.44$ & $6 \cdot 06^{1}$ & 1.30 & $6 \cdot 47^{2}$ & 1.05 \\
\hline Overall & $6 \cdot 50$ & 0.77 & $4.46,6.55$ & $6 \cdot 21^{1}$ & 0.88 & $6 \cdot 59^{2}$ & 0.71 \\
\hline
\end{tabular}

*Different superscripts $(\mathrm{a}-\mathrm{g})$ indicate differences in the perceived importance of reducing sugar intake according to age groups and different superscripts (1 and 2 ) indicate sex differences.

Table 5 Hierarchical regression analysis: general acceptance of interventions designed to reduce sugar intake

\begin{tabular}{|c|c|c|c|}
\hline & $B$ & SE $B$ & $\beta$ \\
\hline \multicolumn{4}{|l|}{ Step 1} \\
\hline Constant & 4.42 & 0.19 & \\
\hline Sex $($ women $=1 ;$ men $=0)$ & 0.30 & 0.07 & $0.13^{\star * *}$ \\
\hline Age & 0.01 & 0.00 & $0.13^{\star \star \star}$ \\
\hline Education (higher $=1 v$. not higher $=0$ ) & 0.17 & 0.08 & $0.07^{\star}$ \\
\hline Children in the household $(1=$ yes; no $=0$ ) & 0.10 & 0.07 & 0.05 \\
\hline \multicolumn{4}{|l|}{ Step 2} \\
\hline (Constant) & 0.65 & 0.33 & \\
\hline Sex $($ women $=1 ;$ men $=0)$ & 0.02 & 0.07 & 0.01 \\
\hline Age & 0.00 & 0.00 & 0.05 \\
\hline Education (higher $=1 v \cdot$ not higher $=0$ ) & 0.08 & 0.07 & 0.03 \\
\hline Children in the household $(1=$ yes; no $=0$ ) & 0.04 & 0.06 & 0.02 \\
\hline Attitudes towards sugar intake reduction in Portugal & 0.28 & 0.04 & $0.21^{\star * *}$ \\
\hline $\begin{array}{l}\text { Importance of reducing sugar intake } \\
\text { (all age groups) }\end{array}$ & 0.37 & 0.04 & $0.29^{* * *}$ \\
\hline Sugar consciousness & 0.09 & 0.02 & $0.14^{\star \star \star}$ \\
\hline Frequency of sugar intake & -0.04 & 0.02 & $-0.06^{\star}$ \\
\hline
\end{tabular}

$R^{2}=0.25 ;{ }^{*} p<0.050,{ }^{* *} p<0.010,{ }^{* \star *} p<0.001$. 
As shown in Table 5, the results of step 1 indicate that general acceptance of the interventions were significantly associated with sex $(p<0.001)$, age $(p<0.001)$ and education $(p=0.034)$, such that higher support was found for women, older participants and those with higher education. Having children in the household was unrelated with the overall acceptance of interventions, $p=0.151$. However, the inclusion of variables related to sugar consumption in step 2 rendered the associations of individual characteristics non-significant. Instead, we found that general acceptance of the interventions was more strongly associated with the perceived importance of reducing sugar intake, attitudes towards reducing sugar intake in Portugal, and by sugar consciousness, all $p$ 's $<0.001$.

\section{Discussion}

Governments worldwide have been implementing policies aiming to improve citizens' health, by discouraging some behaviours (alcohol or tobacco consumption) and encouraging others (exercising, healthier eating). In a recent WHO report, most countries reported having nutrition-relevant policies $^{(34)}$. However, despite this progress, we are far from attaining the goals set in the Global Action Plan for the prevention and control of non-communicable diseases ${ }^{(35)}$, particularly those related to obesity and diabetes. Assessing how individuals perceive such interventions is crucial for different stages of policymaking, from the build-up of political will for governments to take action to the evaluation of their efficacy ${ }^{(11)}$. Previous research suggested that the more intrusive the intervention, the least acceptance it will receive ${ }^{(26-28,31)}$. We focused on interventions aimed at reducing sugar intake, which is still an understudied topic. Portugal offers an interesting context to study this issue because, due to the high sugar intake, several policies have been implemented in recent years ${ }^{(13)}$.

Hagmann et al. ${ }^{(32)}$ found support for most interventions aimed at reducing sugar intake, except for reducing portion sizes, taxation and replacing sugar by artificial sweeteners. Our findings were slightly different as participants were highly supportive of all interventions, except the one related to artificial sweeteners. Still, both studies concur on the most and least supported interventions - labelling of sugar content and replacement of sugar by artificial sweeteners, respectively. Strategies aimed at informing consumers such as nutritional labelling have also obtained the highest levels of approval in other studies ${ }^{(26)}$. The lack of support for sugar substitution by artificial sweeteners is also not surprising, as consumers seem to mistrust the use of food additives, considering them less natural, unhealthy and related to negative health outcomes (for a review, see $\left.{ }^{(36)}\right)$. Still, results from Hagmann et al. ${ }^{(32)}$ suggested that some consumers, namely overweight individuals, may be more supportive of interventions focused on the substitution of sugar by artificial sweeteners. Although this type of sweeteners has been marketed as a healthier alternative to sugar intake, the debate about its benefits is still ongoing. For instance, it has been suggested that while it may contribute to weight reduction ${ }^{(37)}$, some important safety issues have also been detected ${ }^{(38,39)}$. Overall, because the intake of sweeteners has not been consistently associated with health benefits, some dietary guidelines (e.g., in Canada ${ }^{(40)}$ ) proposed that the intake of free sugars should be achieved through the promotion of unsweetened beverages instead.

We also examined how the acceptance of specific interventions may vary according to individual characteristics. In line with other studies, age and sex differences emerged for most interventions, with older participants and women showing higher acceptance overall ${ }^{(25,32)}$. Regarding education level and presence of children in the household, the results were restricted to specific interventions, such that highly educated participants were more in favour of taxation, whereas participants with children in the household were more in favour of advertisement ban for products high in sugar. However, we did not find differences in the acceptance of the intervention according to $\mathrm{BMI}^{(32)}$.

Participants also reported positive attitudes towards the need of reducing sugar intake in the Portuguese population and agreed with the importance of reducing sugar intake across all age groups, particularly among children. Likewise, participants indicated paying attention to the amount of sugar they consume, which was also in line with a low self-reported frequency of consumption of high sugary foods and beverages. Importantly, results from a hierarchical regression analysis showed that all these variables were significantly associated with the acceptance of interventions, particularly attitudes towards the need of reducing sugar intake in Portugal and perceived importance of reducing sugar intake across age groups, over and above social-demographic variables (i.e., age, education and sex). In fact, these results were found independently of any a priori difference according to individual characteristics.

Another important contribution of the current work is the demonstration of which interventions implemented in Portugal are most salient to participants. Although only about one-third of the participants could remember at least one intervention, we still obtained 425 intervention descriptions. The most frequently mentioned interventions were those related to increased prices or taxation for products (particularly beverages) with high sugar content, reduction in the weight of individual sugar packets and limited availability of products offered in healthcare or education facilities. Both the taxation and interventions limiting the availability of sugary products have been recently legislated and implemented in Portugal, whereas the reduction of the individual sugar packets stems from an agreement between health authorities and an association representing the hospitality industry. We can speculate that the salience of this latter intervention may be explained by its 
pervasiveness in everyday life, due to the Portuguese high coffee consumption patterns. Future studies should seek to further explore the information sources regarding these interventions (i.e., press, social media), as well as their perceived impact in consumers shopping and consumption behaviours, including individual strategies to reduce sugar intake (for a review, see ${ }^{(41)}$ ). The labelling of sugar content was spontaneously mentioned by $<2 \%$ of respondents which was surprising given that it received the highest acceptance rating.

In general, our results suggest an optimistic scenario both from a policymaking and a public health standpoints, as our participants were very receptive to the implementation of interventions aimed at reducing sugar intake, reported positive attitudes towards the need of addressing excessive sugar intake and were already paying attention to their own sugar intake. However, we recommend caution in the generalisation of the results to the Portuguese population, as it is possible that this high support is related to specific characteristics of the volunteers who participated in the current study. A participation bias in nutrition-related studies is not uncommon (e.g., women and highly educated individuals are more likely to participate in this type of research ${ }^{(42)}$ ). Indeed, our sample differs from the overall population regarding the level of education and BMI. Specifically, our sample is highly educated (almost $80 \%$ with higher education), whereas the proportion of population (25-64 years old) with tertiary education in Portugal is only $25 \%{ }^{(43)}$. The fact that participants were recruited through a university may have also contributed to such differences in the level of education. Also, almost $60 \%$ of our sample reported a BMI within the normal weight range, which differs from the $43 \%$ found in the overall Portuguese population (although close to the $56 \cdot 1 \%$ found for population with higher education $\left.{ }^{(5)}\right)$. Noteworthy, these results do not provide any evidence regarding the association between the acceptance of a given intervention and its efficacy. For example, a recent study ${ }^{(26)}$ found that although approval for healthy eating interventions was positively associated with perceived effectiveness, it was negatively associated with actual effectiveness. Furthermore, the available evidence regarding the efficacy of interventions aimed at reducing sugar intake is mostly focused on the consumption of specific products (e.g., SSB) or interventions (e.g., taxation ${ }^{(44)}$ ). Therefore, more studies are needed to assess how the implementation of such interventions may contribute to actual healthier food choices.

Another potential limitation of the current study is that most items included broad descriptions of the interventions in terms of the target population, or even the product categories they refer to. Concerning the latter, all the items referred to products with high sugar content in order to include both foods and beverages. However, it is possible that acceptance might differ if the items are framed for SSB or specific food categories. Indeed, policies have prioritised the reduction of SSB intake ${ }^{(8)}$, namely through taxation ${ }^{(45)}$. Consumers may be more prone to accept such interventions, as these types of beverages constitute examples of products consistently perceived as unhealthy. Regarding the target population of interventions, previous studies have shown that individuals are particularly supportive of interventions targeting children ${ }^{(25)}$, which may be important when determining their acceptance. For example, we observed that, although participants are in favour of advertisement ban intervention, this was the second least supported intervention. However, such acceptance level was likely to increase if the ban was directed at products marketed for children (which was actually issued in Portugal very recently $)^{(46)}$. Future studies could also consider including more items to measure acceptability ${ }^{(31)}$, as well as assessing related constructs (e.g., beliefs about the causes of obesity, considering that people who attribute obesity to the food environment tend to be more supportive of policy interventions $\left.{ }^{(24)}\right)$. Another suggestion concerns the inclusion of more detailed measures of frequency of consumption of high sugar foods and beverages, as well as the contexts in which they are consumed.

Intervention acceptance is a crucial issue to consider when planning future policy interventions, and despite the general public being a key audience to assess in this regard, it may also be important to include other stakeholders, such as healthcare professionals, behaviour change experts and politicians. In addition, aspects other than acceptance, such as financial viability, effectiveness, equity and potential sideeffects, are also essential to consider when designing and planning the implementation of such policies ${ }^{(47)}$.

The current study identifies which interventions aimed at reducing sugar intake had higher visibility (as suggested by the free-recall task) and acceptance levels in Portugal. Still, due to the high complexity of the food consumption patterns, it is unlikely that the implementation of one type of intervention alone will suffice to address the issue. Indeed, multiple interventions need to be implemented simultaneously ${ }^{(22)}$ with the aim of contributing to changes in the food culture ${ }^{(6)}$. Moreover, although policies focusing on a single aspect are useful for the reduction of specific additives (e.g., added sugar), they can also be reductionist as they do not focus on overall diet quality ${ }^{(48)}$. Hence, comprehensive policies are needed to address the high levels of sugar intake and foster healthy eating behaviours among populations. Knowledge on how people perceive and accept different interventions for the reduction of sugar intake is an important step towards that end and is vital to support government action in this area.

\section{Acknowledgements}

Acknowledgements: The authors would like to thank Hugo Pais for his help in data collection. Financial support: The current research was financially supported by Project 
LISBOA-01-0145-FEDER-028008, co-funded by the Lisboa 2020 programme, Portugal 2020, and European Union through FEDER (Fundo Europeu de Desenvolvimento Regional/ European Regional Development Fund) funds and by national funds through the Foundation for Science and Technology. Conflict of interest: There are no conflicts of interest to declare. Authorship: Formulation of the research questions and study design: all authors; Data collection: M.P. and C.A.G.; Data analyses: M.P. and D.L.R.; Writing the article: all authors. Ethics of human subject participation: The current study was conducted according to the guidelines laid down in the Declaration of Helsinki, and all procedures involving research study participants were approved by the Ethics Committee of Instituto Universitário de Lisboa (ISCTE-IUL, approval no. 22/ 2019). Written informed consent was obtained from all participants.

\section{References}

1. World Health Organization (2015) Guideline: Sugars Intake for Adults and Children. Geneva: WHO.

2. Mela DJ \& Woolner EM (2018) Perspective: total, added, or free? What kind of sugars should we be talking about? Adv Nutr 9, 63-69.

3. Azaïs-Braesco V, Sluik D, Maillot M et al. (2017) A review of total \& added sugar intakes and dietary sources in Europe. Nutr J 16, 6.

4. Lopes C, Torres D, Oliveira A et al. (2017) National Food, Nutrition, and Physical Activity Survey of the Portuguese General Population 2015-2016: Summary of Results; http://www.ian-af.up.pt/ (accessed September 2019).

5. Lopes C, Torres D, Oliveira A et al. (2017) National Food, Nutrition and Physical Activity Survey of the Portuguese general population. EFSA Support Publ 14, EN-1341.

6. Evans CEL (2017) Sugars and health: a review of current evidence and future policy. Proc Nutr Soc 76, 400-407.

7. Mozaffarian D, Angell SY, Lang T et al. (2018) Role of government policy in nutrition: barriers to and opportunities for healthier eating. BMJ 361, k2426.

8. Popkin BM \& Hawkes C (2016) Sweetening of the global diet, particularly beverages: patterns, trends, and policy responses. Lancet Diabetes Endocrinol 4, 174-186.

9. Cullerton K, Donnet T, Lee A et al. (2018) Effective advocacy strategies for influencing government nutrition policy: a conceptual model. Int J Behav Nutr Phys Act 15, 83.

10. Cullerton K, Donnet T, Lee A et al. (2016) Playing the policy game: a review of the barriers to and enablers of nutrition policy change. Public Health Nutr 19, 2643-2653.

11. Reynolds JP, Archer S, Pilling M et al. (2019) Public acceptability of nudging and taxing to reduce consumption of alcohol, tobacco, and food: a population-based survey experiment. Soc Sci Med 236, 112395.

12. Dispatch No. 3618-A (2016) Diário da República, 2a série - No. 49 [Republic Diary No. 49, Series II]; https:// dre.pt/application/file/a/73833787 (accessed October 2019).

13. Graça P, Gregório MJ, de Sousa SM et al. (2018) A new interministerial strategy for the promotion of healthy eating in Portugal: implementation and initial results. Health Res Policy Syst 16, 102.

14. Dispatch No. 7516-A (2016) Diário da República, 2a série - No. 108 [Republic Diary No. 108, Series II]; https://dre.pt/application/conteudo/74604818 (accessed October 2019).

15. Dispatch No. 11391 (2017) Diário da República, 2a série - No. 248 [Republic Diary No. 248, Series II]; https://dre.pt/application/file/a/114414905 (accessed October 2019).

16. Direção-Geral da Saúde (2019) Programa Nacional Para a Promoção da Alimentação Saudável - 2018/2019 [National Program for the Promotion of Healthy Eating - 2018/2019]. Lisboa, Portugal: Direção-Geral da Saúde; http://www. alimentacaosaudavel.dgs.pt/activeapp/wp-content/files_ mf/1563303731Relato\%CC\%81rio_PNPAS_2019.pdf (accessed October 2019).

17. Law No. 42 (2016) Diário da República, 1a série - No. 248 [Republic Diary No. 248, Series I]; https://dre.pt/application/ file/a/105630354 (accessed October 2019).

18. Law No. 114 (2017) Diário da República, 1a série — No. 249 [Republic Diary No. 249, Series I]; https://dre.pt/application/ file/a/114426182 (accessed October 2019).

19. Law No. 251 (2018) Diário da República, 1a série — No. 251 [Republic Diary No. 251, Series I]; https://dre.pt/application/ file/a/117514660 (accessed October 2019).

20. Goiana-da-Silva F, Cruz-e-Silva D, Gregório MJ et al. (2018) The future of the sweetened beverages tax in Portugal. Lancet Public Health 3, e562.

21. Goiana-da-Silva F, Nunes AM, Miraldo M et al. (2018) Fiscalidade ao serviço da saúde pública: A experiência na tributação das bebidas açucaradas em Portugal [Using pricing policies to promote public health: the sugar sweetened beverages taxation experience in Portugal]. Acta Med Port 31, 191-195.

22. Thow AM, Downs S \& Jan S (2014) A systematic review of the effectiveness of food taxes and subsidies to improve diets: understanding the recent evidence. Nutr Rev 72, 551-565.

23. Diepeveen S, Ling T, Suhrcke M et al. (2013) Public acceptability of government intervention to change health-related behaviours: a systematic review and narrative synthesis. BMC Public Health 13, 756.

24. Beeken RJ \& Wardle J (2013) Public beliefs about the causes of obesity and attitudes towards policy initiatives in Great Britain. Public Health Nutr 16, 2132-2137.

25. Sainsbury E, Hendy C, Magnusson R et al. (2018) Public support for government regulatory interventions for overweight and obesity in Australia. BMC Public Health 18, 513.

26. Cadario R \& Chandon P (2019) Viewpoint: effectiveness or consumer acceptance? Tradeoffs in selecting healthy eating nudges. Food Policy 85, 1-6.

27. Mazzocchi M, Cagnone S, Bech-Larsen Tet al. (2014) What is the public appetite for healthy eating policies? Evidence from a cross-European survey. Health Econ Policy Law 10, 267-292.

28. Reisch LA, Sunstein CR \& Gwozdz W (2017) Viewpoint: beyond carrots and sticks: Europeans support health nudges. Food Policy 69, 1-10.

29. Niederdeppe J, Gollust SE, Jarlenski MP et al. (2013) News coverage of sugar-sweetened beverage taxes: pro- and antitax arguments in public discourse. Am J Public Health 103, e92-e98.

30. Thomas-Meyer M, Mytton O \& Adams J (2017) Public responses to proposals for a tax on sugar-sweetened beverages: a thematic analysis of online reader comments posted on major UK news websites. PLOS ONE 12, e0186750.

31. Petrescu DC, Hollands GJ, Couturier D-L et al. (2016) Public acceptability in the UK and USA of nudging to reduce obesity: the example of reducing sugar-sweetened beverages consumption. PLOS ONE 11, e0155995.

32. Hagmann D, Siegrist M \& Hartmann C (2018) Taxes, labels, or nudges? Public acceptance of various interventions designed to reduce sugar intake. Food Policy 79, 156-165. 
33. Gréa Krause C, Beer-Borst S, Sommerhalder K et al. (2018) A short food literacy questionnaire (SFLQ) for adults: findings from a Swiss validation study. Appetite 120, 275-280.

34. World Health Organization (2018) Global Nutrition Policy Review 2016-2017: Country Progress in Creating Enabling Policy Environments for Promoting Healthy Diets and Nutrition. Geneva: WHO.

35. World Health Organization (2013) Global Action Plan for the Prevention and Control of Noncommunicable Diseases 2013-2020. Geneva: WHO.

36. Szúcs V, Szabó E, Guerrero L et al. (2019) Modelling of avoidance of food additives: a cross country study. Int J Food Sci Nutr 70, 1020-1032.

37. Laviada-Molina $\mathrm{H}$, Molina-Segui $\mathrm{F}$, Pérez-Gaxiola $\mathrm{G}$ et al. (2020) Effects of nonnutritive sweeteners on body weight and BMI in diverse clinical contexts: systematic review and meta-analysis. Obes Rev 21, e13020.

38. Purohit V \& Mishra S (2018) The truth about artificial sweeteners: are they good for diabetics? Indian Heart J70, 197-199.

39. Kakleas K, Christodouli F \& Karavanaki K (2020) Nonalcoholic fatty liver disease, insulin resistance, and sweeteners: a literature review. Expert Rev Endocrinol $\operatorname{Metab} \mathbf{0}, 1-11$.

40. Health Canada (2019) Canada's Dietary Guidelines for Health Professionals and Policy Makers. Ottawa, ON: Health Canada; http://epe.lac-bac.gc.ca/100/201/301/ weekly_acquisitions_list-ef/2019/19-04/publications.gc.ca/ collections/collection_2019/sc-hc/H164-231-2019-eng.pdf (accessed April 2020).
41. Rodda SN, Booth N, Brittain M et al. (2020) I was truly addicted to sugar: a consumer-focused classification system of behaviour change strategies for sugar reduction. Appetite 144, 104456.

42. Andreeva VA, Salanave B, Castetbon K et al. (2015) Comparison of the sociodemographic characteristics of the large NutriNet-Santé e-cohort with French Census data: the issue of volunteer bias revisited. I Epidemiol Community Health 69, 893-898.

43. OECD. Education at a Glance (2019) 2019: OECD Indicators. Paris: OECD Publishing.

44. Kirkpatrick SI, Raffoul A, Maynard M et al. (2018) Gaps in the evidence on population interventions to reduce consumption of sugars: a review of reviews. Nutrients $\mathbf{1 0}$, 1036.

45. Hagenaars L, Jeurissen P \& Klazinga N (2017) The taxation of unhealthy energy-dense foods (EDFs) and sugar-sweetened beverages (SSBs): an overview of patterns observed in the policy content and policy context of 13 case studies. Health Policy 121, 887-894.

46. Law No. 30 (2019) Diário da República, 1a série — No. 79 [Republic Diary No. 79, Series I]; https://dre.pt/application/ file/a/122144588 (accessed October 2019).

47. Michie S, Atkins A \& West R (2014) The Behavior Change Wheel: A Guide to Designing Interventions. London, UK: Silverback Publishing.

48. Mozaffarian D, Rosenberg I \& Uauy R (2018) History of modern nutrition science: implications for current research, dietary guidelines, and food policy. BMJ 361, k2392. 